\title{
EPIDERMOID AND DERMOID TUMOURS OF THE ORBIT*
}

\author{
BY \\ PATRICK C. CAREY \\ The National Hospital, Queen Square, London
}

IN neuro-surgical practice patients presenting with orbital and orbito-cranial lesions are frequently encountered. In every case the nature, the source, and the anatomical extent of the underlying lesion must be ascertained before treatment is begun. Among the many causes of unilateral proptosis (Jackson, 1950, 1951) are epidermoid and dermoid tumours of the orbit. It is the purpose of this paper to review the clinical picture, diagnosis, and treatment of five epidermoid and two dermoid tumours which were encountered in a series of 293 cases of orbital and orbito-cranial lesions seen in the neuro-surgical service of Mr. Harvey Jackson. These five epidermoid and two dermoid tumours comprised 6.3 per cent. of the proven orbital tumours in this same series.

Epidermoid and dermoid tumours consist of two main parts: capsule and contents. The capsule is usually opaque, white, and glistening, but in the case of dermoids may vary from yellow to brown in colour. The contents of epidermoid tumours consist of concentric laminae of keratin and epithelial debris which have a white soapy or waxen appearance, but dermoid tumours may contain in addition to the keratin and epithelial debris, sebaceous material, hair, and oily fluid.

Most investigators agree that both epidermoid and dermoid tumours develop from misplaced epithelial rests, as Remak (1854) first suggested. Horrax (1922) was of the opinion that the degree or the depth of the epithelial layer forming the misplaced epithelial rests determined the type of tumour which might arise from it. Bostroem (1897) stated that the difference depended not only on the actual depth, but also on the embryonic antiquity of the rest, and that a younger and more primitive cell layer would have the characteristics of a dermoid rather than an epidermoid growth. It is logical, as suggested by Critchley and Ferguson (1928), that if only squamous epithelium is included then an epidermoid tumour arises; if, however, the foetal inclusion contains epithelium and dermis, than a dermoid tumour with fat cells, sebaceous glands, sweat glands, and hair follicles develops.

* Read at the combined meeting of the Society of British Neurological Surgeons and the 36th Annual Meeting of the Irish Ophthalmological Society in Dublin, May 16-18, 1957. 
Many authors advocate a common term to describe epidermoid and dermoid tumours. This is because of many similarities of the tumours in aetiology, sites of origin, mode and rate of growth, and possible complications. "Pearly tumour", a name first suggested by Cruveilhier (1829), is based on the appearance which he likened to a "metallic sheen like silver, or a pearl of the finest water". While such a graphic description holds good in the case of epidermoid tumours, it is often inaccurate in the case of dermoids, which may be yellow, brown, or even red in gross appearance. "Cholesteatoma", a term suggested by Müller (1838) because of the presence of cholesterol crystals in the contents of both tumours, lacks precision as many types of tumour, other than epidermoids and dermoids, contain cholesterol crystals. To name a growth from its essential features has much to recommend it and I have therefore, retained the terms epidermoid and dermoid. I appreciate that, owing to the technical difficulties of their surgical excision, these tumours often have to be removed in fragmentary fashion, that frequently only parts of the capsule of the tumour may be submitted to histological examination, and that the portion examined may not be representative of the whole (Figs 1, 2, and 3).

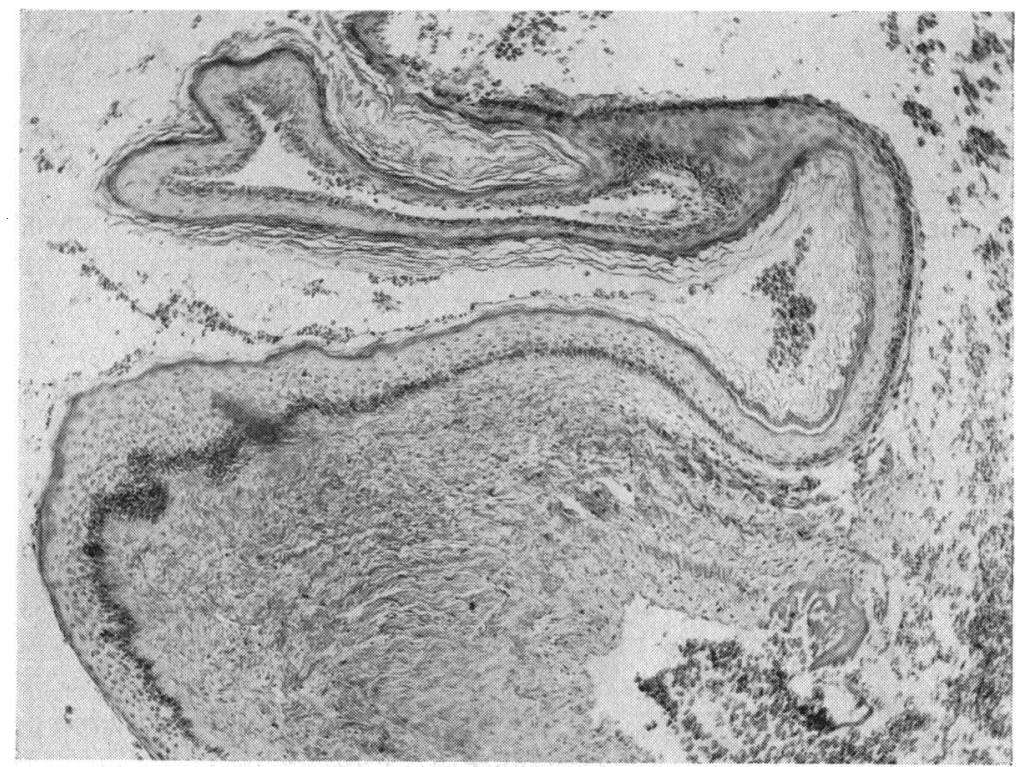

FIG. 1.-Case 4, a typical epidermoid tumour. The connective tissue wall is devoid of such structures as sebaceous glands, sweat glands, and hair follicles. It is lined by stratified squamous epithelium and contains keratin.

\section{Case Reports}

Case 1, a housewife aged 26, had a swelling in the outer half of the right upper eyelid for 11 years. She had become aware of prominence of the right eye $3 \frac{1}{2}$ years ago owing to the contact of the eyelashes against the lens of her sunglasses. Blurring of vision and diplopia on lateral gaze to the right of 3 months' duration caused her to seek treatment. 


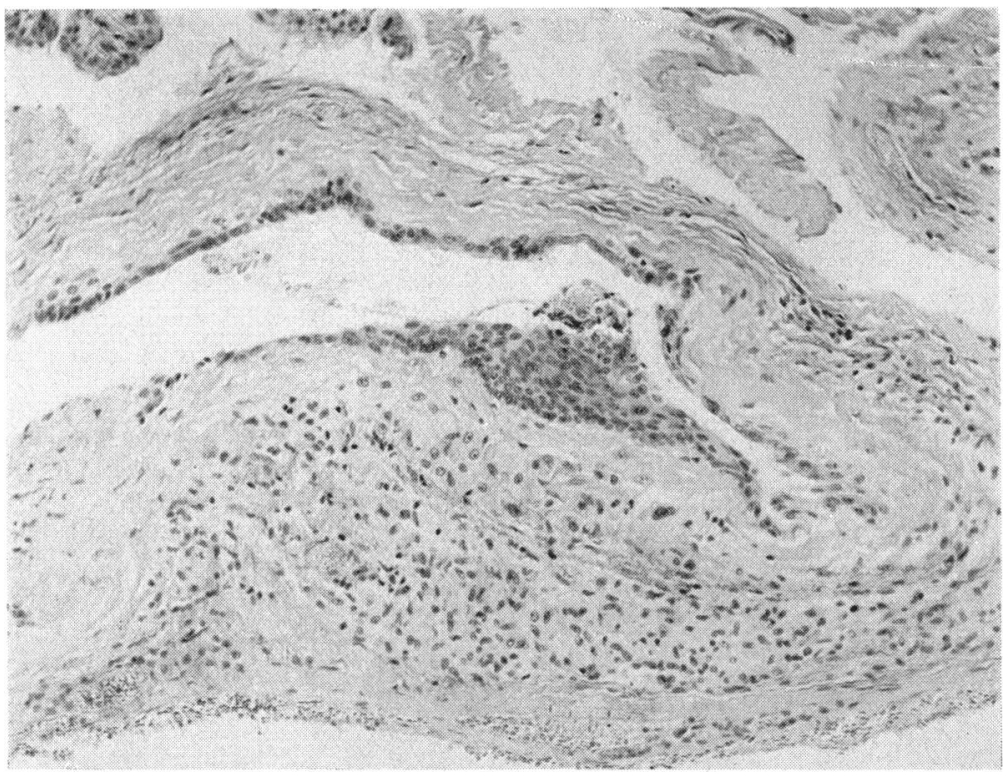

Fig. 2.-Case 2, an epidermoid tumour, showing the variation of the depth of the stratified squamous epithelium which may be encountered in these tumours.

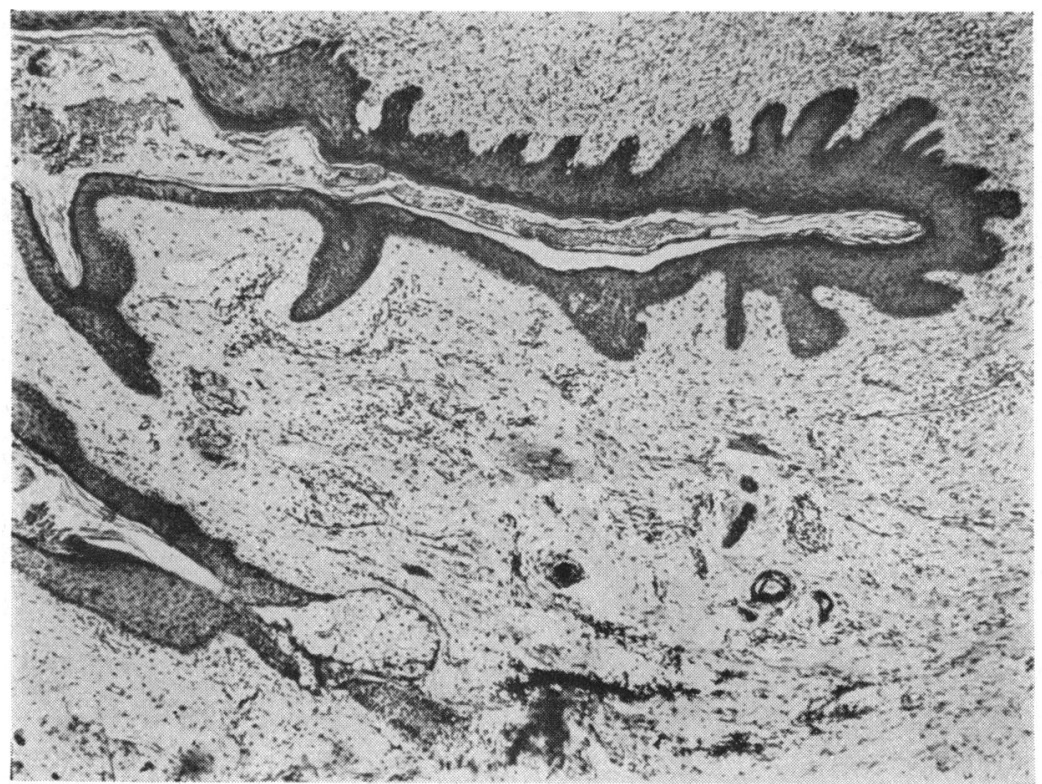

Fig. 3.-Case 7, a dermoid tumour, showing a sebaceous gland and hair follicle in addition to the squamous epithelium (From Jackson, 1945, p. 588).

Examination.-The right eye was displaced forwards, downwards, and medially (Fig. 4, overleaf). The anterior edge of a firm, fixed deep-seated nodular mass was palpable beneath the outer third of the supra-orbital margin. The irreducible proptosis 


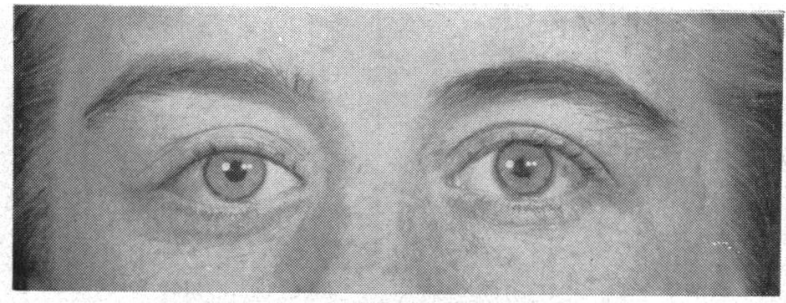

FIG. 4 Case 1, epidermoid tumour of right orbit. A swelling is visible in the outer half of the upper eyelid. The eye is displaced forwards, downwards and medially.

measured $8 \mathrm{~mm}$. The tumour mass was visible on elevation of the upper eyelid in the outer canthus (Fig. 5). Vision was 6/6 in both eyes. External ocular movements were full, but diplopia was present on horizontal gaze to the right. The fundi were normal.

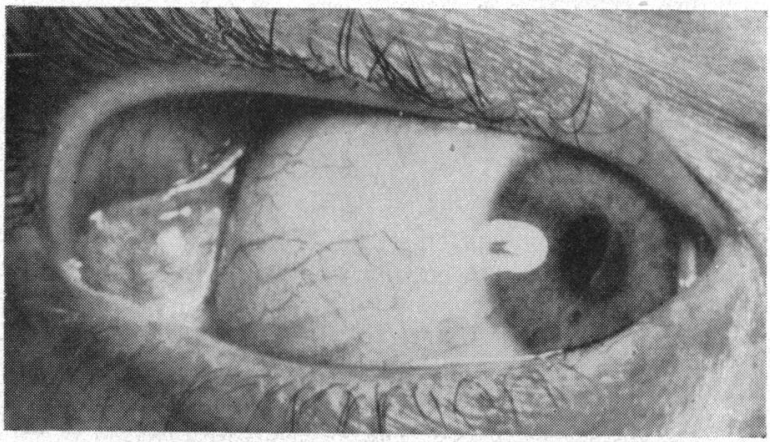

Frg. 5.-Case 1, tumour visible in outer canthus.

Plain $x$ ray (Fig. 6) disclosed an elliptical, clear-cut translucent defect, surrounded by bone of increased density, in the supero-lateral margin of the orbital roof behind the zygomatic process. The zygomatic process appeared thickened.

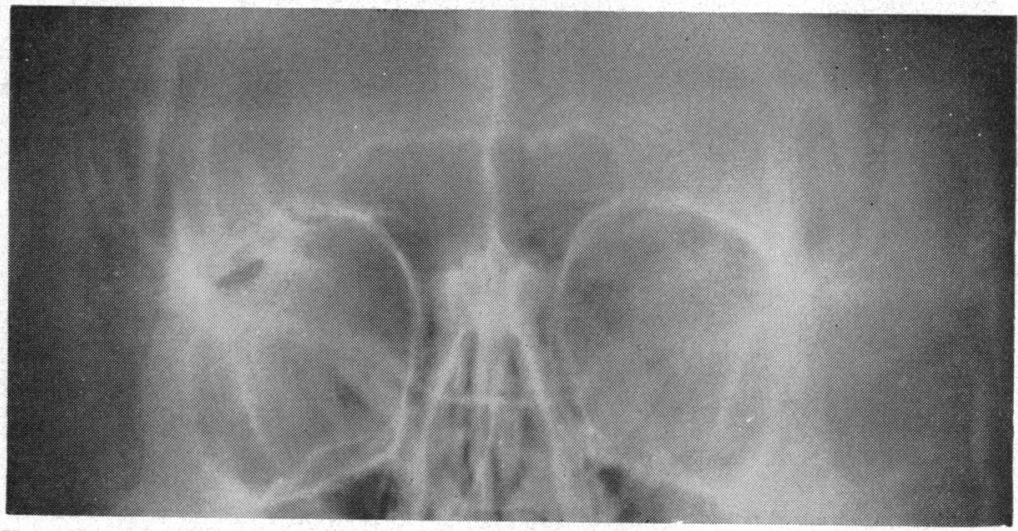

FIG. 6.-Case 1, skull radiograph, showing clear-cut defect surrounded by bone of increased density in right orbital roof.

On lateral view (Fig. 7, opposite) in addition to the defect in the orbital roof, there was an area of increased translucency extending into the lateral wall of the anterior cranial fossa. 
FIG. 7.-Case 1, lateral view, showing an area of increased translucency extending into the lateral wall of the anterior cranial fossa from the defect in the orbital roof.

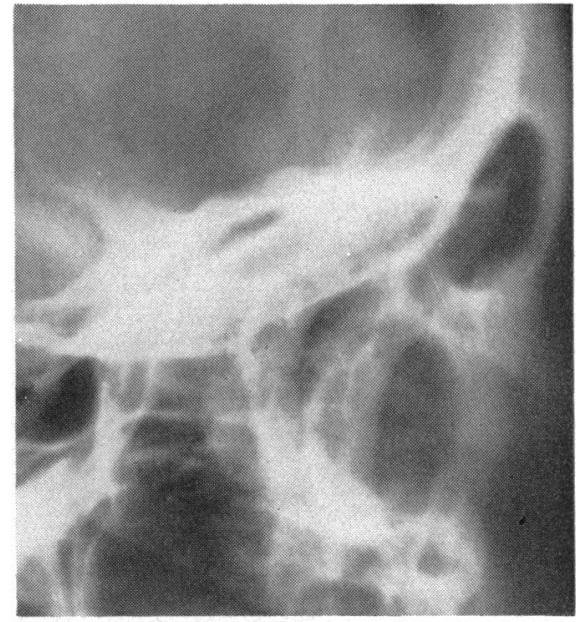

Operation.-The orbit was approached by the lateral route (H.J.). On removal of the lateral wall of the orbit, solid white cheesy material escaped. When this debris was removed, the capsule of the tumour was seen lying outside the orbital fascia and extending posteriorly from the lacrimal gland. The dura mater on the under surface of the frontal lobe, exposed during the operation, was not adherent to the tumour at the site of the bony defect in the orbital roof.

Pathology.-Sections of the wall of the tumour showed a fibrous structure with a partial lining of squamous epithelium. The picture was that of an epidermoid tumour.

Result.-After operation the eye returned to a normal position and there was no diplopia. Within the last month, 18 months since operation, she has had a small infected swelling in the right eyelid. It is not accompanied by proptosis. It is probably a recurrence and may be associated with the radiological translucency in the lateral wall of the anterior fossa which was not explored during the first operation.

Case 2, a wage clerk aged 23 years, had had a prominence of the left eye since childhood. Recurrent bouts of watering of the eye had commenced $3 \frac{1}{2}$ years before admission. The lacrimal duct had been repeatedly dilated but found to be patent. The epiphora was then attributed to the proptosed eye and the patient was referred for treatment.

Examination.-The left eye was displaced forwards, downwards, and medially (Fig. 8).

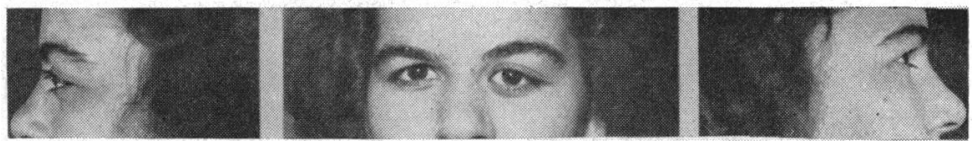

Fig. 8.-Case 2, epidermoid tumour of left orbit, showing characteristic displacement of the eye which had been present since childhood.

The proptosis measured $6 \mathrm{~mm}$. In the outer half of the upper lid a firm swelling in relation to the orbital roof was palpable. Upward movement of the left eye was limited and accompanied by diplopia. Visual acuity was $6 / 18$ in the left eye and $6 / 6$ in the right. The fundi and fields were normal. 
$X$ rays (Fig. 9) revealed a faint translucent area surrounded by bone of increased density involving the supero-lateral margin of the orbital roof and extending forwards for a short distance into the frontal bone at the root of the fronto-zygomatic process.

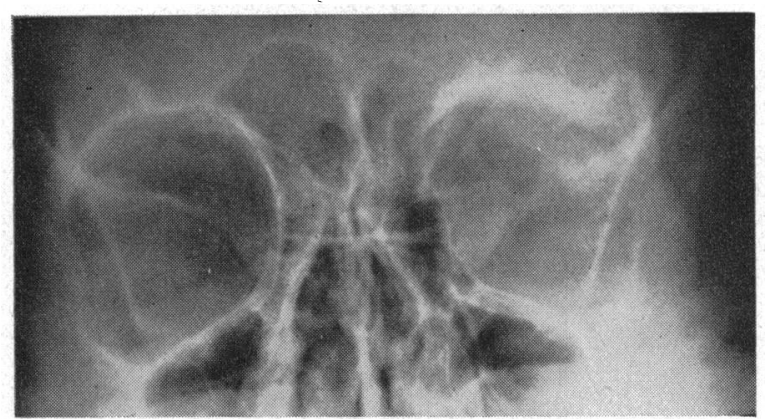

Fig. 9.-Case 2, skull radiograph, showing defect in left orbital roof. It is surrounded by bone of increased density, the margin of which extends forwards for a short distance into the frontal bone at the root of the fronto-zygomatic process.

The defect was also seen on lateral view (Fig. 10).

FIG. 10.-Case 2, lateral view, showing defect in orbital roof.

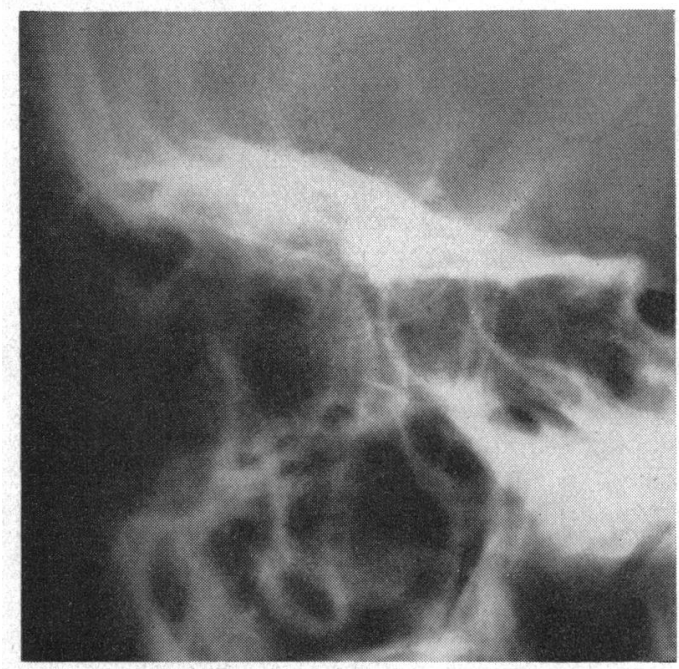

Operation.-The orbit was approached by the lateral route (H.J.). On removal of a thin lateral wall of the orbit, semi-fluid contents escaped. The thin capsule of the tumour, which lay behind the lacrimal gland and external to the orbital fascia, was removed in fragments. Owing to uncertainty of complete removal of all the capsule, the tumour bed was swabbed with Zenker's solution.

Pathology.-The tumour was formed by fibrous tissue lined by a thin layer of epithelial cells. The picture was that of an epidermoid tumour as shown in Fig. 2.

Result.-Post-operatively the proptosis was reduced and there was no further watering of the eye. Visual acuity in the left eye was still 6/18. The patient developed a partial ptosis after operation which needed subsequent surgical correction.

Case 3, a shopkeeper aged 51 years, had been hit in the left eye by a rubber ball 2 months previously. One week later he had first noticed protrusion of the left eye.

Examination.-The eyeball was displaced forwards and downwards (Fig. 11, opposite). The irreducible proptosis measured $8 \mathrm{~mm}$. Photographs taken 25 years ago showed 


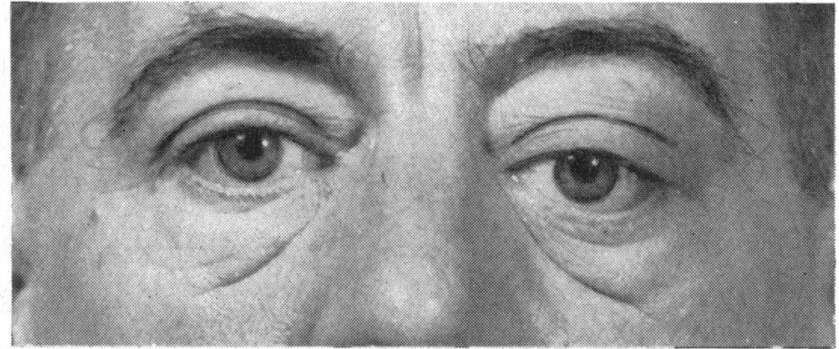

Fig. 11.-Case 3, epidermoid tumour of left orbit. The eye is proptosed and displaced downwards and medially.

proptosis (Fig. 12). The visual acuity was 6/9 in both eyes. Upward movement and abduction of the left eye was limited at extremes. The visual fields and fundi were normal.

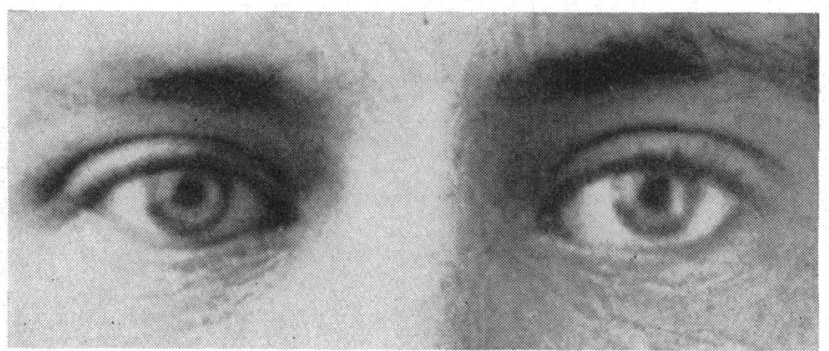

Fig. 12.-Case 3, photograph taken 25 years previously, showing proptosis of the left eye.

$X$ ray (Fig. 13) showed a large oval translucent defect in the lateral wall and roof of the orbit involving the greater and lesser wings of the sphenoid bone. The margins of the defect were sclerotic and sharply defined. The fronto-zygomatic process was broadened and involved in the radiological changes.

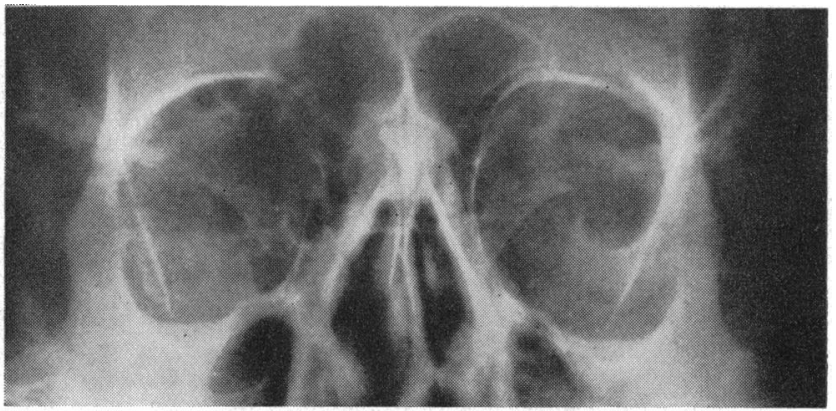

FIG. 13. - Case 3, large oval translucent defect in roof and lateral wall of left orbit. The left fronto-zygomatic process is broadened.

Operation.-Frontal craniotomy and removal of lateral wall of orbit were carried out (H.J.). The lateral wall of the orbit was paper thin. A glistening tumour lay external to the orbital cone. Through the defect in the greater wing of the sphenoid bone, the wall of the tumour was adherent to the dura mater covering the temporal lobe in the middle cranial fossa. The tumour contents were evacuated and the capsule excised.

Pathology.-The fibrous tissue in the capsule of the tumour showed evidence of a 
chronic inflammatory reaction and was infiltrated by macrophages, round cells, and occasional multinuclear giant cells. The cells lining the tumour were squamous in character. The tumour exhibited the histological features of an epidermoid with chronic inflammatory reaction in the fibrous tissue around it.

Result.-Post-operatively a good cosmetic result was obtained. Follow-up has only been a year. Recurrence is deemed unlikely owing to the certainty of complete excision.

Case 4, a housewife aged 59 years, had had a severe cold 3 months ago, during which she complained of blurring vision. Her husband then noticed a prominence of the left eye which had gradually increased from that time.

Examination.-The left eye was displaced forwards, medially, and downwards (Fig. 14). An ill-defined mass was palpable above the globe of the eye. An irreducible proptosis measured $9 \mathrm{~mm}$. The patient had a tower skull. The visual acuity was $6 / 6$ in the right eye and $6 / 9$ in the left. The visual fields and fundi were normal. Upward movement and abduction and adduction of the left eye was defective.

FIG. 14.-Case 4, epidermoid tumour of left orbit with gross displacement of the eye.

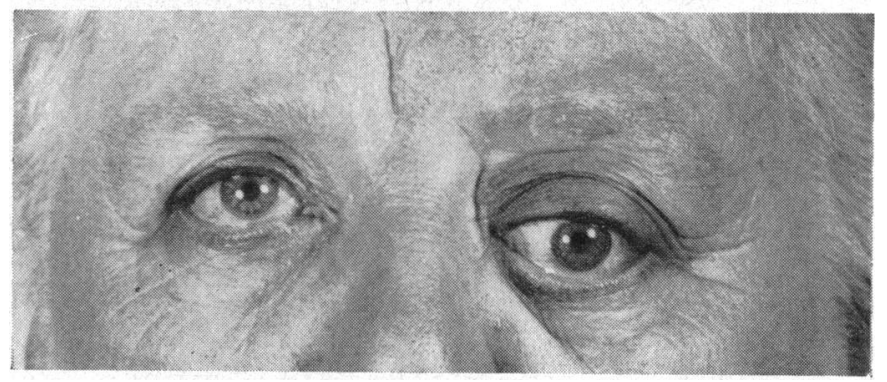

$X$ rays (Fig. 15) showed that the margins of the defect were sharply defined and surrounded by bone of increased density.



Fig. 15.-Case 4, skull radiograph, showing bone defect with clearly defined margins. This epidermoid tumour had penetrated the dura mater of the anterior and middle cranial fossae.

The lateral view (Fig. 16, opposite) showed turricephaly and a large translucent defect in the roof and lateral wall of the orbit.

Operation.-The anterior approach was used (H.J.), and an incision below the eyebrow exposed the tumour. An incision in its wall released a large quantity of liquifying white waxy epithelial debris. The tumour was cleared of its contents and its capsule dissected out. This exposed the defect in the bone of the roof and posterior wall of the orbital cavity. The tumour had extended through the dura, and the cortex of the frontal and temporal lobes was prolapsing through the bony defect. The wound was packed with ribbon gauze soaked in Zenker's solution and allowed to heal by granulation.

Pathology.-Cultures of tissue from the tumour yielded a growth of Staphylococcus aureus. Histologically the picture was that of an epidermoid tumour as shown in Fig. 1. 
FIG. 16.-Case 4, lateral view, showing turricephaly and a large defect in the orbital roof surrounded by bone of increased density.

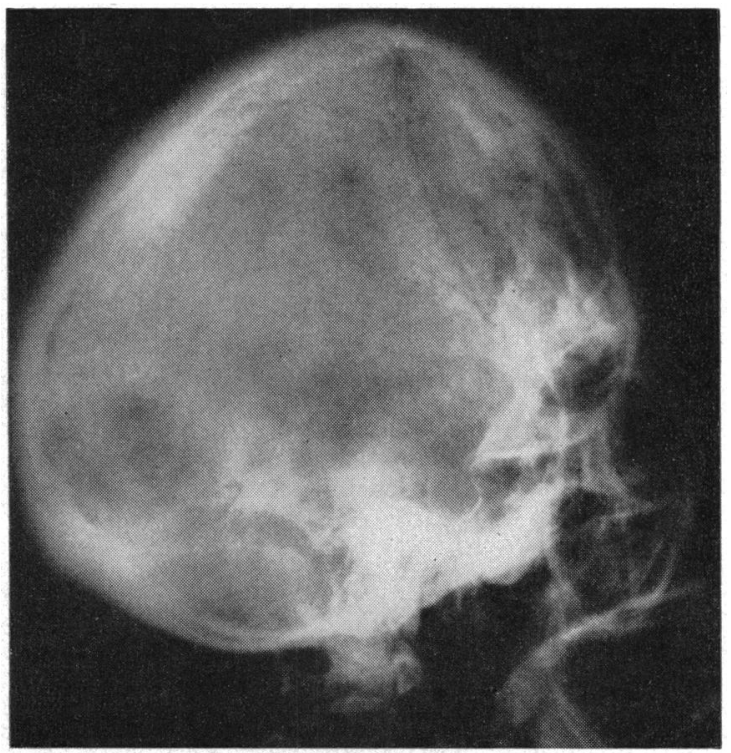

Result.-Post-operatively the eye returned to a much improved position with full external ocular movements. The immediate post-operative period was complicated by a troublesome dysphasia. No frank meningitis developed-as is frequent on removal of such a tumour when situated intradurally. The dysphasia took 2 months to resolve.

Case 5, a housewife aged 39 years, had noticed 21 years ago that she could not see on the right side as the right eye could not turn into the corner; 12 years ago she had doveloped diplopia on lateral gaze to the right, and for the past 6 years the right eye had not moved laterally beyond the midline. For one year vision in the right eye had been steadily diminishing.

Examination.-There was a moderate degree of proptosis of the right eye. The visual acuity was $6 / 9$ in the left eye, but in the right eye only doubtful finger counting was present in the temporal half of the visual field. There was macular diplopia. The right visual field was full peripherally, but showed a pericentral scotoma which had enlarged to include the blind spot and had extended beyond it. There was a preponderance of the defect in the nasal half field. The left field was full apart from a slight temporal depression (Fig. 17, overleaf).

Hughes (1954) states that this type of visual field is characteristic of extrinsic compression of the optic nerve. Mooney and McConnell (1949) have pointed out that only lesions close to the optic canal produce such changes and they relate it to fixation of the optic nerve in the canal. The absence of a field defect in Cases 1 to 4 above-in all of which the tumour was situated more anteriorly-rsupports this view.

$X$ rays (Fig. 18, overleaf) showed a clear-cut defect in the postero-lateral region of the right orbit. There was sclerosis of bone at its margins, and a diffuse absorption of the right optic foramen. The posterior clinoids of the sella turcica were decalcified.

Operation.-Right frontal craniotomy (H.J.) showed that the roof of the orbit was thin and eroded. This and the greater part of the lesser wing of the sphenoid bone was removed and exposed a glistening white tumour capsule, lying externally to the muscle cone and passing posteriorly from the orbital cavity extradurally into the middle cranial fossa, where it lay alongside the pituitary fossa. The contents of the tumour, which resembled soft cheesy material, were removed, and the majority of the capsule, which was 


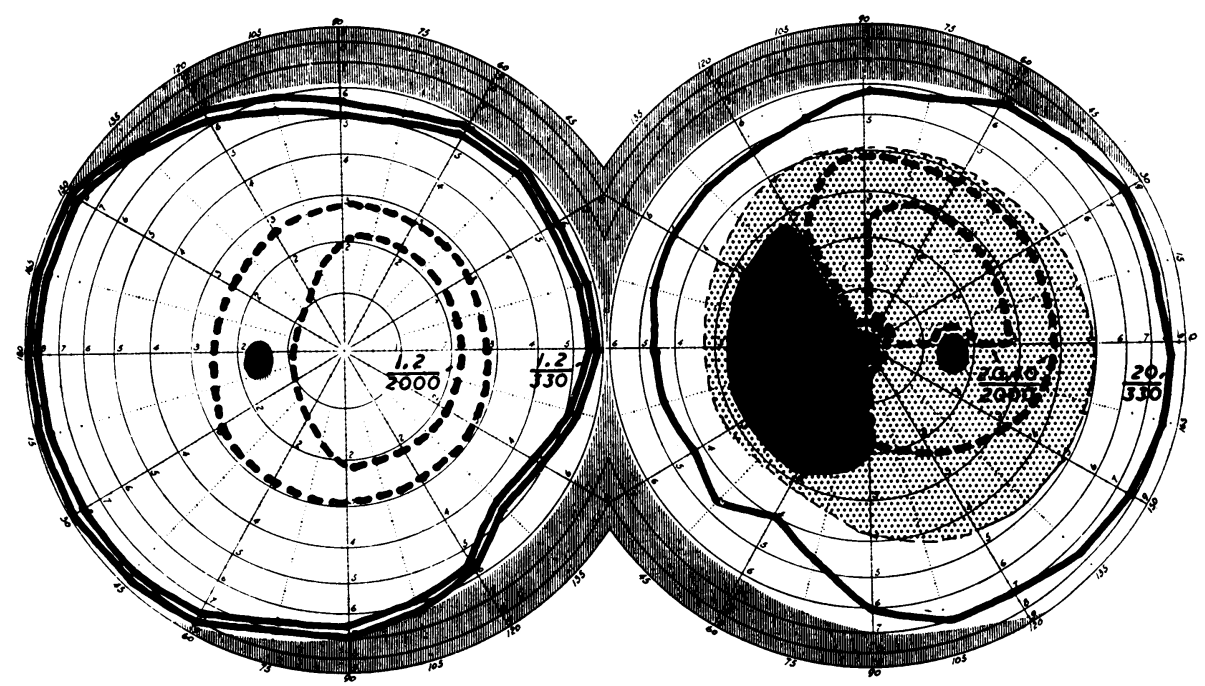

FIG. 17.-Case 5, visual fields, showing a central scotoma which has enlarged to include the caecal area and extend beyond it, indicating compression of the optic nerve by an epidermoid tumour of the right orbit (From Hughes, 1954, by permission of Blackwell Scientific Publications).
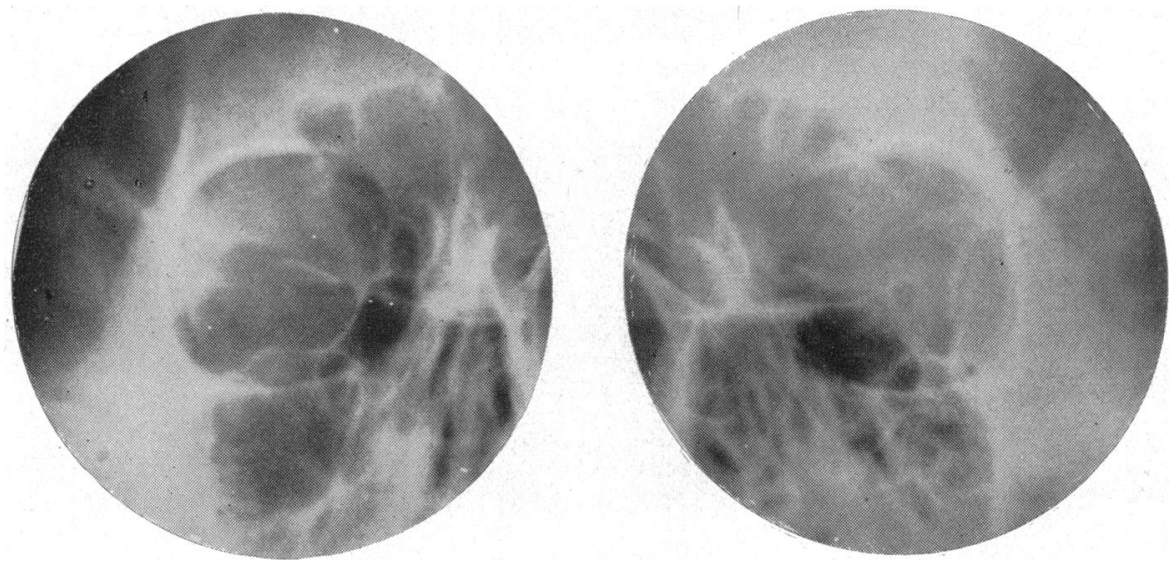

FIG. 18.-Case 5, radiographs of optic foramina. A defect with sclerotic margins is present in the postero-lateral region of the right orbit. There is diffuse absorption of the right optic foramen,

adherent to the dura mater, was excised. This exposed the second division of the right trigeminal nerve passing into the foramen rotundum. Remnants of the capsule alongside the pituitary fossa were left in situ.

Pathology.-The tumour was an epidermoid.

Result.-Post-operatively the patient made a good recovery, and in the third postoperative week it was recorded that she had a visual acuity of $6 / 60$ in the right eye. The visual fields (Fig. 19) then showed a recession of the pericentral scotoma and only a slight depression remained in the upper nasal field. There was blunting of pinprick over the right side of the nose and the right side of the hard palate and gum. The patient has not been seen since her discharge from hospital. 


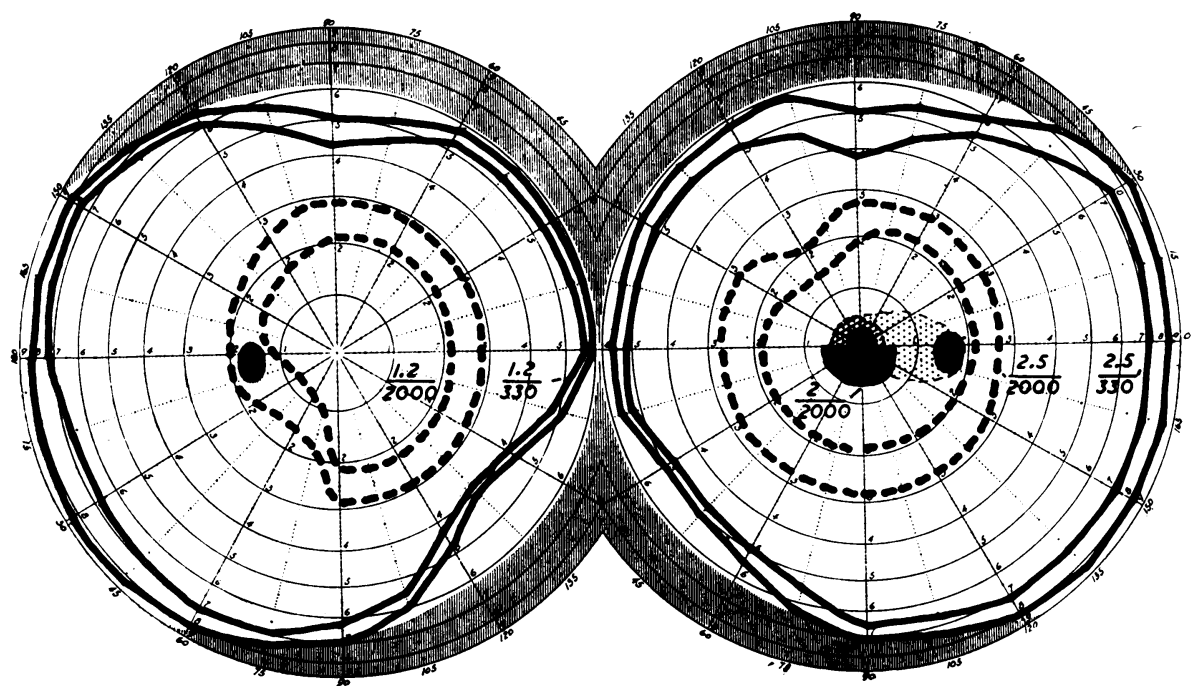

FIG. 19.-Case 5, visual fields in the third post-operative week after removal of an epidermoid tumour, showing recession of scotoma (unpublished diagram provided by Prof. Brodie Hughes).

Case 6, an apprentice compositor aged 17 years, had noticed a swelling in his left upper eyelid for 5 years. It had steadily increased in size. For 2 years he had noticed his left eye to be lower than the right (Fig. 20).

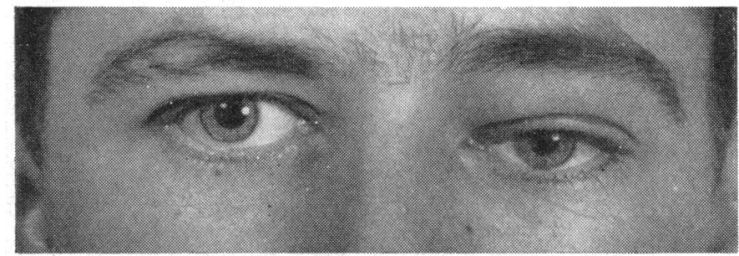

FIG. 20.-Case 6, dermoid tumour of left orbit. This was the only tumour to contain hair.

Examination.-There was a visible lump between the left eyelid and eyebrow (Fig. 21).

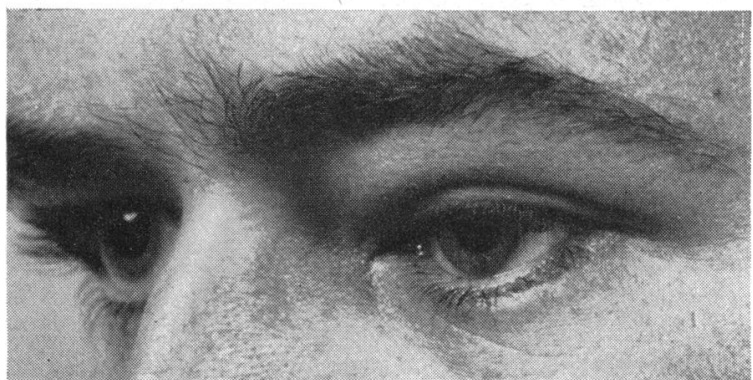

FiG. 21.-Case 6, tumour visible in medial half of upper eyelid.

The eyelid had a swollen appearance. The lump, the size of a cherry, was smooth and cystic to palpation and was attached to the inner wall of the orbit. The eyeball was depressed but there was no proptosis of the globe. There was a reduction of upward movement of the eye. The visual acuity and visual fields and fundi were normal. 
$X$ rays showed no abnormality (Fig. 22).

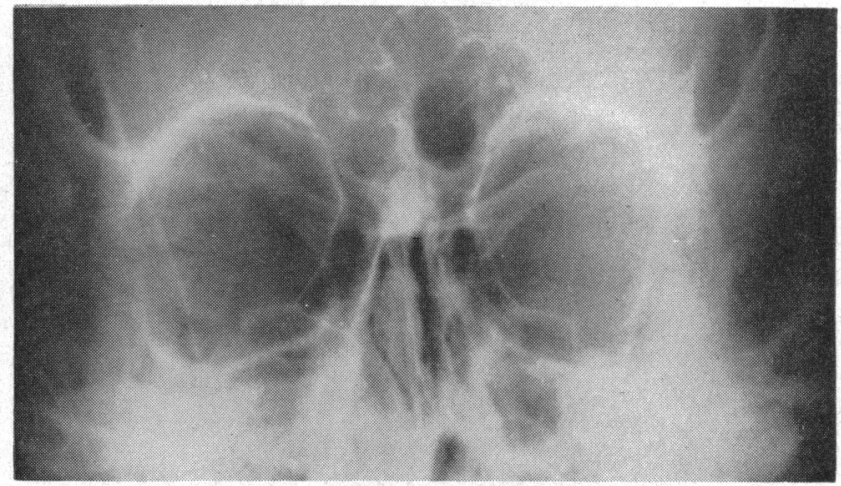

FIG. 22.-Case 6, $x$ ray showing no abnormality. This was the only case without radiographic changes.

Operation.-Anterior approach was used (H.J.), and a plum-coloured encapsulated tumour was encountered deep to the supero-orbital margin of the frontal bone, lying between the orbital fascia and the periosteum of the medial wall of the orbit. The capsule was inadvertently opened in dissection of the tumour and creamy sebaceous material containing hair escaped. The contents of the tumour were evacuated and the capsule excised. The periosteum of the medial wall of the orbit at the site of the tumour was noticeably thickened.

Pathology.-The tumour had the features of a dermoid cyst, containing sweat glands and hair. In addition there were collections of round cells and multinucleated foreignbody giant cells in the tumour wall. A thin layer of calcified material and a fragment of bone lay at the margin of the tissue.

Result.-Post-operatively a good cosmetic result was obtained, and the external ocular movements were full. There has been no evidence of any recurrence.

Case 7, a farmer aged 51 years, had first noticed prominence of the left eye 17 years ago. This had become steadily worse, and 2 months before admission he had had troublesome watering of the left eye and had also noticed a lump in the left temple. He had sought medical advice and biopsy of the swelling in the left temporal region had been taken. The following report was made on the material submitted to the pathologist:

"This is some sort of granuloma. Whether it is associated with a generalized disorder such as Schüller-Christian disease one cannot say, though the history might guide one".

After the biopsy the patient was referred to Mr. Harvey Jackson.

Examination.-There was a moderate proptosis of the left eye which was displaced forwards, downwards, and medially (Fig. 23). The eyelids were oedematous. In the outer third of the lower lid there was a sinus discharging pus. An ill-defined swelling was present in the left temporal fossa. The swelling was soft, fluctuant, and pulsating. Pressure on the swelling had not produced pus from the sinus. The visual fields and fundi were normal. The visual acuity was $6 / 6$ in both eyes.

$X$ rays (Fig. 24) showed a defect which resembled that described by Dandy (1942) as typifying a case of Hand-Schüller-Christian disease. It was, however, a clear-cut defect in the lateral wall and roof of the orbit, with sclerotic margins and resembled the radiological appearances of the other cases in this series. 
Fig. 23.-Case 7, dermoid tumour of left orbit with proptosis, oedema of eyelids, discharging sinus in lower eyelid near outer canthus, and boss in left temporal region (From Jackson, 1945, p. 588).
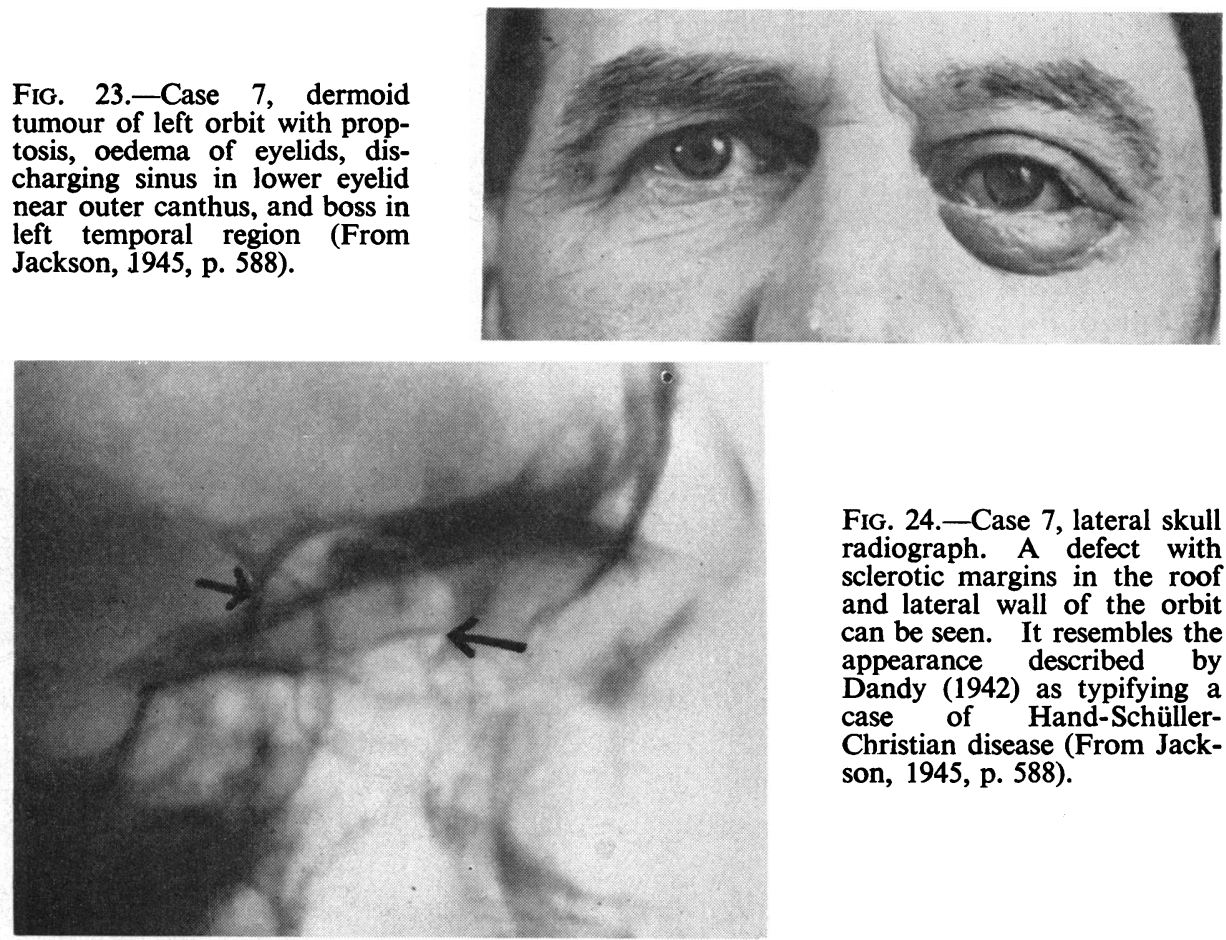

Fig. 24.-Case 7, lateral skull radiograph. A defect with sclerotic margins in the roof and lateral wall of the orbit can be seen. It resembles the appearance described by Dandy (1942) as typifying a case of Hand-SchüllerChristian disease (From Jackson, 1945 , p. 588).

Operation.-A vertical muscle-splitting incision was made in the left temporal fossa (H.J.). Beneath the temporal muscle, a tumour was encountered and opened. A large quantity of sebaceous material was evacuated. There was no evidence of pus formation. The tumour was lying inside the orbit and had made a smooth circular opening in the lateral wall of the orbit through which a portion of the tumour bulged in dumb-bell fashion. Medial to the tumour the orbital cone was intact. Posteriorly, the tumour had eroded bone, exposing the dura mater covering the frontal and temporal lobes, but the dura mater was intact. The tumour bed was packed with ribbon gauze soaked in $1 / 80$ carbolic and the wound allowed to heal by granulation.

Pathology.-This tumour exhibited the features of a dermoid tumour as shown in Fig. 3.

Result.- In the third and fifth post-operative years, the patient had an infected swelling at the site of the sinus in the lower eyelid. On the first occasion this spontaneously discharged pus and healed, and on the second occasion it necessitated incision.

\section{Summary}

A brief account is given of current views of the origin and the nature of epidermoid and dermoid tumours. Most authors believe that they arise from cell rests; the dermoid from cell rests containing epithelial and dermal elements, the epidermoid from rests containing squamous epithelium.

Both epidermoid and dermoid tumours consist of a capsule and its contents. Though both tumours have a white glistening appearance, dermoids may show variation in colour. Epidermoid tumours contain no true dermal elements and their capsule is lined by squamous epithelium and keratin; dermoids are distinguished by the presence of such structures as fat cells, 
sweat glands, sebaceous glands, and hair follicles in the wall of the tumour.

The terms "pearly tumour" and "cholesteatoma" have been used in the literature to describe both epidermoid and dermoid tumours because of their many similarities. A preference for the retention of the more definitive terms epidermoid and dermoid based on their histological features, has been expressed.

The clinical features, the radiological changes, the operative findings, and the pathology of five epidermoid and two dermoid tumours have been described.

Treatment was sought by two patients because of prominence of the eye, by two more because of watering of the eye, by a further two because of impairment of vision, and by one because of a swelling in the eyelid. In six of the seven patients, proptosis of the eye was a prominent feature. The proptosis was painless and irreducible and its average duration was 13 years. There was, in addition to the proptosis, a downward and medial displacement of the eye, as the tumours were usually situated in the supero-lateral quadrant of the orbit. The mechanical obstruction occasioned by the size and situation of the tumour caused impairment of external ocular movements in four patients, but only one complained of double vision. In five patients a palpable tumour mass was situated between the globe of the eye and the superior margin of the orbit. A visual field defect and pallor of the optic disc was observed in one patient. Examinations of the fundi were normal in the six other patients.

Radiological examination of the orbit demonstrated a lesion in the bony wall of the orbit in six patients. In three of these, the lesion involved contiguous parts of the frontal and sphenoid bones, in two it was confined to the frontal bone, and in one to the sphenoid bone. In one patient, no radiological abnormality was demonstrated. The characteristic of the lesion shown on plain $x$ ray was a bony defect with a smooth demarcated edge associated with thickened sclerotic bone. The radiological findings were of diagnostic significance in these tumours.

All seven tumours were treated by surgical excision, the indications being the disfiguring proptosis and extension of the lesion beyond the confines of the orbit. Extension of the tumour from the orbit into the cranial fossae had occurred in four patients. In three of these, the tumour was adherent to the dura mater. In one, it had extended intradurally and resulted in a troublesome dysphasia in the post-operative period, but was not complicated by a frank chemical meningitis as is a feature of these tumours associated with the central nervous system.

Varying surgical approaches were used; the operation of choice is an osteoplastic frontal craniotomy combined with removal of the lateral wall of the orbit. It provides adequate access to the tumour in the orbit and its extension into the anterior and middle cranial fossae, and gives a good postoperative cosmetic result. The anterior approach, tempting as it may be in 
an anteriorly palpable tumour, gives inadequate access to the tumour. Two of such palpable tumours in this series had extended into the middle cranial fossa. Krönlein's lateral approach, which gives a limited exposure and tends to leave an ugly depression at the side of the orbit, was not employed in these patients. Jackson's lateral approach gives a good cosmetic result and is adequate for tumours confined to the orbit but it is restricted in access to the possible extension of these tumours.

Histologically five of these tumours were epidermoid and two dermoid.

Two suspected recurrences after surgical treatment were noted. One was attributed to inadequate excision of involved bone, and the other to superadded infection before treatment.

It is submitted that the clinical features, together with the associated radiological changes, differentiate these tumours as a clinical entity from the many causes of unilateral proptosis of the eye. Complete surgical excision of these tumours is usually possible and gives a gratifying result.

It is my wish to record my thanks to Mr. Harvey Jackson for access to his clinical material and his helpful advice. I wish to thank Dr. W. Blackwood for the histological reports, Dr. Hugh Davies for the radiographs and their reports, Prof. Brodie Hughes for permission to use Fig. 19, and Mr. A. H. Prickett and Mr. J. A. Mills for preparing the photographs. Fig. 17 is reproduced by courtesy of Blackwell Scientific Publications and Figs 3, 23, and 24 by courtesy of the Editors of the Proceedings of the Royal Society of Medicine.

\section{REFERENCES}

Bostroem, E. (1897). Z Zbl. allg. Path. path Anat., 8, 1.

CRITChley, M., and Ferguson, F. R. (1928). Brain, 51, 334.

CRUverLhier, J. (1829). "Anatomie pathologique du corps humain", vol. 1, bk 2, pl. 6. Baillière, Paris.

DANDY, W. E. (1942). “Orbital Tumours". Lewis, London.

HorraX, G. (1922). Arch. Neurol. Psychiat. (Chicago), 8, 265.

HuGHES, B. (1954). "Visual Fields", 1st ed., p. 111. 'Blackwell, Oxford.

JACKSON, H. (1945). Proc. roy. Soc. Med., 38, 587. (1950). Trans. ophthal. Soc. U.K., 70, 73. (1951). Ann. roy. Coll. Surg. Engl., 9, 123.

Mooney, A. J., and McConnell, A. A. (1949). J. Neurol. Neurosurg. Psychiat., $12,205$.

MülleR, J. (1838). "Ueber den feinern Bau und die Formen der krankhaften Geschwülste", p. 50. Reimer, Berlin.

RemaK, R. von (1854). Cited by Critchley and Ferguson (1928), p. 337.

\section{ADDITIONAL BIBLIOGRAPHY}

Feld, M., and Guillaumat, L. (1952). Sem. Hôp. Paris, 28, 3664.

FORREST, A. W. (1949). Arch. Ophthal. (Chicago), 41, 198.

GigGlBerger, H. (1949). Klin. Mbl. Augenheilk., 114, 206.

GODTFREDSEN, E. (1953). Bibl. Ophthal. (Basel), No. 38 (Fortschr. Augenheilk., II), p. 133.

HARBERT, F. (1949). Arch. Ophthal. (Chicago), 42, 451.

KING, J. E. J. (1939). Ann. Surg., 109, 649.

KREJCI, F. (1950). Mschr. Ohrenheilk., 84, 195.

LAWRENCE, G. A. (1949). J. Tenn. med. Ass., 42, 385.

MONTRESOR, D. (1949). Riv. oto-neuro-oftal.'(Bologna), 24, 381.

NicholLs, R. F. (1950). Arch. Ophthal. (Chicago), 43, 189.

PaGani, M. (1951). Rass. ital. Ottal., 20, 402.

PAufiQue, L., and ÉtIENNe, R. (1949). Bull. Soc. Ophtal. Fr., $1,854$.

PAUL, M. (1953). Brit. J. Ophthal., 37, 114.

PFeIFFer, R. L., and Nicholl, R. J. (1948). Arch. Ophthal. (Chicago), 40, 639.

TYTUS, J. S., and PENNYBACKER, J. (1956). J. Neurol. Neurosurg. Psychiat., 19, 241.

ThACKER, E. A. (1950). Arch. Otolaryng. (Chicago), 51, 400. 